\title{
Confronting Classifications - When and What is Vernacular Architecture?
}

\author{
Neasa Hourigan \\ Architecture and Civil Engineering, School of Planning, Queens University Belfast, Northern Ireland
}

Copyright $@ 2015$ Horizon Research Publishing All rights reserved.

\begin{abstract}
The study of the vernacular in architectural research seems to wage a continuing battle against accusations of antiquarianism, romanticism and simply the questioning of its relevance and boundaries. Some theorists have proposed that vernacular architecture could be more usefully defined through consideration of usage patterns that occur after the completion of the built form rather than the study of the original building intent. This non-reliance on original objectives is somewhat in conflict with researchers who would situate vernacular architecture as irredeemably domestic and contend that it was in an effort to make buildings 'great' from their first conception that architecture as a formal discipline evolved. ${ }^{[1]}$ Vernacular, primitive, traditional, folk and the description of architecture as 'ordinary' or 'every day' are terms that have all been used to denote 'non pedigreed' architecture since Marc-Antoine Laugier's work of the eighteenth century. ${ }^{[2]}$ It is the aim of this paper to explore the many, and sometimes contradictory, classifications of the vernacular and what lies ahead in this field of research. Successive academics in the field, from the earliest studies of the vernacular, have agreed that this type of building is one that does not remain static and is often characterized by its ability to adapt and transform itself to new usages. ${ }^{[3,4]}$ The vernacular maybe shaped over time by the utilitarian requirements of its occupants and indeed all functioning cultures concomitantly synthesize both tradition and innovation in everyday life as a necessary component of development. ${ }^{[5]}$ However if we characterize the vernacular as belonging to a place we must surely omit the strip malls of the present; typifying them as 'everyday' prohibits the inclusion of the handcrafted, lovingly maintained home and if we require that such buildings evidence adaptation by occupants we must ignore the developer kit houses mushrooming up all around us. It is the authors conclusion that the concept of vernacular is fundamentally linked to the social, economic and environmental history of a given region or nation. As a result it is vital that regional interpretations of the vernacular are preserved and allowed to be fluid across academic spheres in a manner not dissimilar to the subject matter itself.
\end{abstract}

Keywords Architecture, Vernacular, Classification,
Traditional, Ordinary

\section{Introduction}

The term vernacular and its associated vocabulary such as 'traditional', 'everyday', local, indigenous are not clearly defined in subject or interpretation across academic disciplines. The topic of the vernacular straddles a number of fields from language to anthropology to architecture and as a result this review of the current literature confines itself to peer reviewed professional literature from reliable library stocked journals and key texts from the history of architecture and environment theory. This methodology is considered appropriate for a paper that considers the academic language around the vernacular although the author recognizes that a more complex reading is necessary in order to study the use of similar terms in their common usage. The descriptive search terms used to locate appropriate work is expanded on within the paper. The relevance of sources was considered in terms of how reliable the author's work was and whether it contributed to the research question. As the paper concerns itself with the first usage of some terms there are a number of older books and papers cited.

In 1886 Henry Van Brunt, the successful American architect and essayist, stated that; 'the vernacular....that which accompanies the first advances of civilization into the new lands ... is merely preliminary to architecture, though for the moment it pretends to be the real thing, ${ }^{[6]}$ Some of the first identifications of a group of building typologies and construction methods as 'vernacular' emerged during the nineteenth century with a focus on tradition and folkloristic culture largely triggered by the cultural flux of industrial revolution. ${ }^{[7,8]}$ The definition of what sections of the built environment may be included within the study of vernacular architecture has evolved to address this consideration of romantic, peasant authenticity as an inextricable aspect of the typology and continues to be the subject of debate amongst academics. 
During the early half of the twentieth century largely solitary studies on vernacular building typologies or regions of particular interest to the authors was undertaken. ${ }^{[9]}$ However such studies were the fledgling work of a field of study that continues to seek a clear definition of itself. ${ }^{[10]}$ In the developed West a concern for the continued existence of local building traditions was fully established by the onslaught on traditional rural and urban fabric of the massive post war housing developments of the $1950 \mathrm{~s} .{ }^{[11]}$ While some attributed this renewed interest as indicative of a consolidation of national identity following such a significant conflict others have aligned the growth in interest as part of a larger movement within academia to consider the social or civic history of nations in greater depth. ${ }^{[12]}$

The first comprehensive text focused on the study of 'vernacular architecture', or what building types and landscapes this terminology should include, is Bernard Rudofsky's 'Architecture without Architects'. ${ }^{[13]}$ The published work is subtitled 'A Short Introduction to Non-Pedigreed Architecture'. This relegation of the vast majority of the built environment to the status of 'mongrel', though seemingly pejorative in outlook, was in actuality a step forward in the recognition of vernacular building design as a meaningful branch of architectural history. The study of vernacular architecture has traditionally polarized into two distinct spheres of interest: a focus on the European indigenous buildings of rural landscapes or peasant conurbations and a fascination with the primitive structures of 'exotic landscapes and cultures being colonized abroad' ${ }^{[14]}$ The last thirty years have seen the study of vernacular architecture, if still largely on the periphery of architectural history, beginning to situate itself away from a 'folkloristic emphasis on preindustrial construction and ethnicity' towards a broader definition and more interdisciplinary approach. Our conception of what constitutes 'vernacular architecture' has evolved greatly since this early era of study when Pevsner stated that "“A bicycle shed is a building; Lincoln Cathedral is a piece of architecture. $"[15]$

\section{Identification- What Vernacular is and What it is not}

It may be useful at this point to consider, in deference to Pevsner, where we locate our understanding of vernacular architecture or indeed whether it is commonly accepted as architecture at all. However well used the idiom, recognition of Wotton's interpretation of Vitruvius' dictum- 'Fine building hath three things, commodity, firmness and delight' persists as the basis of architectural enquiry. ${ }^{[16]}$ Frampton, in his influential essay Labour Work \& Architecture decries this definition as woefully inadequate. Instead he suggests that, though functionally imperfect, architecture may be thought of on 'at least two distinct levels of interpretation: the act of edification of stately structures and the process of building, ${ }^{[17]}$ As will be discussed below whilst most definitions of vernacular architecture do not include the former meaning they do encapsulate the latter.

At its root the word 'vernacular' connotes vulgar or common and emerged as a term in the $17^{\text {th }}$ century to differentiate from 'polite' society in an era when an emerging middle class led to the stratification of social order ${ }^{[18]}$ Early theorists such as Lethaby and Morris emerged as part of the Arts and Crafts movement which sought a return to artisanal values in the built environment and which, inevitably, engendered a renewed focus on traditional ways of building. This portrayal of the vernacular as the inverse of high art/ architecture and that all monumental buildings could be omitted from any study of the field persisted and remained a fundamental aspect of research in vernacular architecture until very recently. ${ }^{[19]} \mathrm{A}$ common classification of vernacular architecture is one that is constructed by a people whose culture or traditions have influenced the finished structure. It often includes the proviso that these typologies have been evolved and perfected over extended periods of time and by generations of builders. ${ }^{[20]}$

This focus on tradition and culture evolved over time implies a myriad of implicit and explicit conditions be present in order for a building to be truly vernacular. The first of these stipulations is that the building is largely conceived and executed by amateurs and predominantly utilizes local materials in a manner that refers to existing buildings in his/her locality. In fact an early study omitted from consideration all urban buildings, all buildings erected after 1840 and all structures that could be categorized in studies of the time as of the 'Great House Class'. (A secondary feature of this seminal study was the absence of any in depth surveys of the buildings as it was 'felt to be unnecessary for buildings of few and simple elements repeated again and again with a comparatively small number of variations'. Similarly Paul Oliver's comprehensive 'Encyclopedia of Vernacular Architecture of the World' defines the term as 'related to their environmental contexts. ${ }^{[21]}$ Oliver contends that previous studies on the vernacular, dating from the nineteenth century onward, were predominantly undertaken by architects and antiquarians and focused on 'the documentation, classification and naming of historic or traditional building forms, materials and styles'.

It may be constructive at this point to consider the distinction within the sphere of vernacular architecture between the 'vernacular', 'traditional' and 'folk' as these three terms are the most commonly interchangeable terminologies within the field. A description that seems representative of the way in which many authors view the 'traditional' in architecture is McKinnell's description during a lecture at MIT of 'accumulated experience, continuous usage: the way things have always been done'. The dictionary definition of traditional is 'the handing down of statements, beliefs, legends, customs, information, etc., from generation to generation, especially by word of mouth or by practice'. ${ }^{[22]}$ It can be difficult to validate traditional values through a consideration of existence over time- some traditions survive millennia while others are merely a few 
decades old. ${ }^{[23]}$ Some of the most widely read texts addressing surviving building stock do not employ vernacular as a term but substitute terms such as 'traditional' or 'historic' in its place. ${ }^{[24]}$ However the group of buildings to which such work refers is largely the same. Alexander categorizes buildings into two subsets; 'all those traditional buildings, built for thousands of years, in traditional societies all over the world' and 'all those buildings built in the last hundred years, built by a totalitarian technology, by industry'.

Similarly the use of the word traditional to identify buildings that could also be categorized as vernacular has in the past, and remains, popular among researchers and authors who concentrate on the architectural history of a particular country, race or building typology. Indeed many of these widely read texts use a variety of the terms listed above to describe the same group of buildings and there are in existence a raft of publications titled 'The Traditional Architecture of ....' or, for example 'African Traditional Architecture' where all the classifying terms become largely interchangeable. ${ }^{[25,26]}$ Terms such as 'primitive' are often more easily positioned within the academic arena. Other authors are quite clear in the description of the word as referring to 'the buildings of preliterate societies...whose industry is handcraft and whose tools are pre-Iron Age'. ${ }^{\text {[2] }}$

The use of the word folk is more common in work that refers significantly to cultural traditions and socio-historical influences and largely appears in studies that predate the foundation of groups dedicated to the study of vernacular architecture. ${ }^{[28]}$ It is important to note that while both the conception and usage of terms within this area of study is undertaken in varying manners across the globe there exists a marked difference between the definition of the vernacular amongst inhabitants and academics of the New World (the United States, South America, Australia and Canada) and that of the Old World (Europe, Asia etc). ${ }^{[29]}$ The former group tends towards a more fluid, dynamic and inclusive definition of the term vernacular which to some extent aligns with the different nature of the building stock available for study.

Possibly the most inclusive of definitions is one that considers the vernacular as any composite part of the built environment that has largely been ignored by the traditional arenas of architectural history. Vernacular architecture could be everything not considered to be 'noble architecture and architectural nobility'. Hitherto the word 'vernacular', when used in relation to architecture, evolved during the $19^{\text {th }}$ century to predominantly describe 'traditional rural buildings of the preindustrial era' in contrast to the architect designed post renaissance built environment. ${ }^{[30]}$ However, since the latter half of the $20^{\text {th }}$ century, the term has been extended to include common building of many and almost all styles: 'mass produced, middle-class housing......industrial building, the architecture of fast food and other commercial franchises... anything not obviously the product of an upper-class, avant garde, aesthetic movement'. Therefore the most accurate characterization of the vernacular is to define the term by what it is not- a preferred aesthetic- rather than what it is.

Possible the most well established proponents of this definition of the vernacular are Venturi et al. who, in their book 'Learning from Las Vegas' attempted to challenge the blithe orthodoxy of contemporaneous architectural theory and thought. ${ }^{[31]}$ (This re-appropriation of the ordinary American landscape was pre empted in some regard by J.B Jackson's earlier Other Directed Houses essay. ${ }^{[32]}$ The book proposed to view the built environment of Las Vegas, already significantly untethered from historical analysis through the verity of its newness, as an amalgamation of utility and sociological intent that is largely free from non-commercially led aesthetic considerations. Commentators at the time objected strenuously to this reading of a wholly developer led, capitalist theme park city as one worthy of serious urban research. ${ }^{[33]}$ The 'decorated shed', devoid of intellectual subtext or professional aestheticism, was simply beneath comment for most academics and authors of the day.

A parallel aspect of this thinking is the implicit, or indeed explicit, social stratification of architectural history as an inevitable by-product of a field so overwhelmingly influenced by the fortuitous survival of particular artifacts. The remnants of buildings from past ages are principally that of the civic, religious or ornamental. The grand and the great are simply more visible and immediate for study by historians and therefore study undertaken on this topic is skewed accordingly. However, just as the scholarly exploration of history has begun to shift towards the chronicling of the lives of ordinary people so architectural history must account for the undue focus on the monumental and aristocratic built environment. ${ }^{[34]}$

Similarly this section of the built environment could be delineated simply as principally the product of constraints, whether economic, environmental, cultural or spatial in contrast to an architecture that seeks to refer to other, more diffuse, motives. ${ }^{[35]}$ Where once these constraints took the form of available materials and technological skill they are now no less influential for taking the form of urban density, availability of transport or the regulatory system. However while the basis for such architecture is utility the final built product cannot be accounted for without some consideration of individual preference or communal preference. The characterization of the vernacular as one of bare utility only tangentially informed by cultural, stylistic preference is rudimentary although this notion exists in some of the earliest texts on the subject. ${ }^{[36]}$

\section{Classification by Author or Occupant}

A progression to this characterization of the vernacular is to include, as a default position, those buildings that have not been conceived as part of the professional output of a certified architect. $^{[37]}$ Almost all nations now have a professional body for the registration of architects and a 
means by which they can certify their work. However the title of 'Architect' has until relatively recently been a rather fluid concept. Kostof dates the 'profession' of architect to the third millennium $\mathrm{BC}$ as evidenced by the existence of graphic conventions for the construction of buildings from even before that era ${ }^{[38]}$ Although architectural practice was an acknowledged profession in the classical world the renaissance saw the establishment of the architect as intellectual rather than the master builders of the Gothic period. Certified architects as we recognize them today, with the creation of a guild-like professional body, and as part of an elite of building experts date from Sebastian Serlio's role in the royal building projects of $16^{\text {th }}$ century France. The increase in scale and complexity of both domestic and non-domestic buildings, particularly since the mid-1800s, has necessitated the establishment and codification of principles for those specializing in the design of buildingsthe density of use and structural ambition require a comprehensive and an explicit set of skills. ${ }^{[39]}$

Architects, when engaged for a construction project, have traditionally occupied a central role in its completion as design visionary, project manager, client advocate and contract administrator. ${ }^{[40]}$ One point of confusion for the Western world's appreciation of vernacular architecture is the tendency to align the profession of architect with mathematics or art when it is often aligned in other cultures with 'spiritual, ceremonial or even curative functions'. The relationship of professional architects to traditional building and vernacular typologies is mired in accusations of intellectual protectionism and elitist disengagement from normative socio cultural values. Yet it may be argued that the elevation to a profession of 'making buildings' requires a rejection of normative values and the legitimization of the architect and his/her architecture only through recognition by similarly, hierarchically placed peers. Successive well-read texts, such as Pevsner's quote, have casually and unapologetically relegated vernacular design to the realm of the primitive or the aesthetically unsophisticated provision of basic shelter. Indeed one of the first studies of traditional building typologies in the United Kingdom, conducted by Lord Raglan, proposed that much of the structural and material innovation evident in the vernacular was a result of the masses appropriating style and technique from a societal elite. ${ }^{[41,42]}$

The idea that vernacular architecture is a spontaneous act by an owner builder is an abiding myth and one that is challenged by the evidence in vernacular studies of 'highly trained individuals' implementing 'complex building traditions'. Theorists have suggested that the removal of lay designers from the history of vernacular architecture stems from a conflict between the modern architects' conception of architecture as a medium which 'promoted the liberation of the individual's creative spirit by breaking down conventional patterns of thought' and vernacular's 'handing down of knowledge, a passing on of doctrine'. ${ }^{[43]}$ In this regard the vernacular may be thought of as the work of many hands rather than one expert- 'a communal art, not produced by a few intellectuals or specialists but by the spontaneous and continuing activity of a whole people with a common heritage, acting under a community of experience ${ }^{\left[{ }^{[4]}\right]}$ The vernacular process of building could be delineated as a subset or series of artisans working to produce a normative standard or facsimile under the guidance of a client/ owner of master builder who innovates or deviates from accepted norms only when utility of functions or the necessity of site requires it. Indeed this version is similar to Christopher Alexander's assertion that traditional architecture occurs at the interface between an adherence to regional conventions and a dynamic interaction with a given site.

Based on current theory, as explored above, the identification of a building as vernacular does not preclude the involvement of a design/build specialist in whatever form that may take. Even if we could limit the definition of the vernacular to that which is not produced by architects or building designers it would not address the vast array of other building professionals, such as bricklayers, carpenters etc, and their contribution to the built process. Indeed the study of vernacular architecture is characterized by inter-discipliniarity because the subject comprises object oriented, social oriented, culture oriented and symbol oriented studies undertaken by social and economic historians, geographers, topographers, archeologists, sociologists and, of course, architectural historians.

The vernacular builder, or indeed architect, has until recently been subject to romantic and antiquarian depictions as someone who, like a vernacular speaker, has evolved in place, within a culture 'by growing up, living, and dwelling in a particular place at a particular time,. ${ }^{[45]}$ However within vernacular traditions it is common to employ specialists to carry out certain parts of the construction. The thatcher in Ireland or the enjarradoras plasterer in Mexico, would be considered 'vernacular' building methods under any of the various definitions discussed in this paper ${ }^{[46]}$ It is also common to find vernacular construction technologies and approaches to material use transplanted across communities as and when they are deemed useful. Even the conception of vernacular as a craft based skill has been largely debunked by the recognition across the world of the importance of prefabricated design and the appropriation and adaptation by unskilled individuals of readymade building elements in the formation of decidedly unique and personal housing. ${ }^{[4]}$

Ultimately, if we conceive of an architect as an individual who, through skill and activity, creates structures for others to inhabit there is no 'qualitative or quantitative' deviation between the role of lay builder and that of professional architect. ${ }^{[48]}$ It is therefore not possible to classify buildings deemed to be vernacular architecture based on the identification of author.

Some theorists have proposed that vernacular architecture could be more usefully defined through consideration of usage patterns that occur after the completion of the built form rather than the study of the original building intent. This non-reliance on original objectives is somewhat in 
conflict with those who would characterize vernacular architecture as irredeemably domestic and contend that it was in an effort to make buildings 'great' from their first conception that architecture as a formal discipline evolves. Upton states that, in an echo of Lefrebvre and de Certeau's socio- politicization and subsequent reorientation of the field of urban design towards complex readings of power relations between users, researchers of architecture might 'subdivide the built environment, not into categories of high and low, or monumental and vernacular, or by types and styles, but into spaces that encourage or discourage certain types of activities'. In a comment on Upton's work Susan Garfinkel proposed the consideration of the vernacular as defined by performance 'at the site of shared meanings created through use ${ }^{[49]}$ This interpretation of vernacular architecture would remove the consideration of era and construction typologies from the field of research allowing for a more cultural and environmental, contextual reading. Through this prism vernacular architecture becomes 'qualitative not quantitative' and could be more distinctly considered as a process driven entity with a focus on the 'how' rather than the 'what'.

Wells similarly concludes that contemporary considerations of 'vernacular architecture' address the subject as 'less a kind of building than an approach to looking at building'. ${ }^{[10]}$ This would suggest that it is the method by which we study the built environment that denotes its characterization. Various sociologists and anthropologists have suggested that our interpretation of the built environment as a cultural and societal construct is often more a reflection of contemporary concerns than an objective analysis. In his consideration of the influence tradition has had on his own work Venturi quotes T.S Elliot's suggestion that tradition is not 'timid adherence' in following the example of previous generations but provides the creative individual with a historical perception, making them 'more acutely conscious of his place in time, of his own contemporaneity'. ${ }^{[31]}$

This acceptance of fluidity in our understanding of vernacular usages would certainly challenge the belief in static, primitive typologies that characterizes the early years of research in this field. The vernacular is shaped over time by the utilitarian requirements of its occupants and all functioning cultures concomitantly synthesize both tradition and innovation in everyday life. ${ }^{[50]}$ Far from being ossified by the weight of accumulated tradition it would seem that vernacular buildings are in fact the site of dynamic innovation, not least due to the utilitarian basis on which such environments are largely undertaken. Stuart Brand articulates this succinctly as 'Growth follows a simple goal of property owners: maximize what you control' ${ }^{[51]}$ This tendency towards 'open-ended', additive forms can be identified as in direct opposition to the largely final, conceptual set pieces of the architect designed building and certainly supports an argument for characterizing typologies through usage. ${ }^{[29]}$

A curious but effective example of the above is the inclusion of aspects of the built environment that have been appropriated by the vernacular- that is adapted and reimaged through local or regional intervention. In commenting on the work of J.B Jackson, Gwendolyn Wright asserts that all study of the vernacular 'embodies a hybridity based on ingenious adaptations to multiple constraints'. ${ }^{[14]}$ Certainly this aspect of architectural crossbreeding is currently being explored by historians of architectural styles that heretofore have been recognized as international and, in the case of the classical villa, a precursor to one version of modern, non-regional, aestheticism. ${ }^{[33]}$ It may be that these building types become, over time, reclassified as 'vernacular variants rather than ideal types'. ${ }^{52]}$

Indeed it is the case that many regions now boast less traditional buildings than buildings that have been made to appear traditional or folklorized. ${ }^{[53]}$ One version of this method of appropriation is the mimicking of traditional architectures using non-traditional methods. Vernacularised modern buildings (modern construction or design techniques and adaptations that mimic local styles) are indicative of the cross fertilization that continues to occur between the contemporary aesthetic of professional architects and the 'dynamic and creative processes that result from cultural encounters, borrowings and conjunctions' within the vernacular tradition. ${ }^{[5,33]}$

Interestingly the murkiness of this interaction, between design the vernacular and the non-vernacular, has led to an increasing appreciation among architects and building professionals of the efficiency and adaptability of vernacular typologies. While traditional construction methods have always been of interest increasingly aspects such as seasonal usage patterns, site-specific design and building occupant responsiveness are of renewed relevance. Those who have proposed a return to more traditional building methods and design techniques are careful not to characterize this as a 'reversion to an architecture which accepts tradition unthinkingly'. ${ }^{[55]}$ Rather work focuses on a return to some of our pre-modern design strategies that allowed for a synthesis of 'tradition, habit and imitation'. This new focus on the life of buildings, their evolution over time and how they respond to both the environment in which they are situated and user needs, is in direct conflict with Rudofsky's 1964 portrayal of the vernacular as never subject to 'fashion cycles' and 'nearly immutable'. ${ }^{[13]}$

\section{Classification through Place or through Native Order}

The study of the vernacular through usage and context in part demands that the design and construction have evolved to, in some way, address regional climate, local norms and setting- led environmental demands. These may be explored as deviations from the constraints that the prevailing building culture and social constructs such as religious and class institutions have already added to the formation of the built artifact. ${ }^{[56]}$ Perhaps this characterization is most clearly illuminated when Alexander states that the nature of the 
'ageless' way of building comes 'simply from the fact that every part is whole in its own right' and deviations from straight lines happens not due to inaccuracy but from an accurate reading of site in alliance with function. ${ }^{[24]}$

This would suggest a characterization of the vernacular as architecture produced as a result of access to means or as Peter Guillery puts it 'traditional building practice may often be a product of an absence of choice'. ${ }^{[34]}$ However as the same text also points out 'contextualism and the vernacular' are not one in the same just as context and modernism are not mutually exclusive. Many vernacular building methods and design methodologies were transported across regions and skills sets taught across cultural boundaries- the use of brick, the method by which particular timber junctions were completed- often share a common heritage that belies a purely regional outlook. ${ }^{[57]}$

Wright states that the vernacular is defined by its nature as indigenous or native to a 'particular district' and 'concerned with the routines and improvisations of everyday life' in that place. ${ }^{[14]}$ One aspect of the classification of vernacular architecture has been the specificity to place of the built artifact or its evolution through proximity to similar forms. This characterization of the vernacular would propose that more than being rooted in a place this architecture is formed of its place and therefore both the tectonics and material expression, overtime, are inextricable from it. 'Vernacular buildings and setting are regionally distinct, regionally representative and regionally understood'. ${ }^{[57]}$ In Mumford's Sticks and Stones he extols the virtues of New England vernacular architecture as singularly suited to their position and displaying a 'cumulative' depth of expression. ${ }^{[58]}$ It is also considered by Christian Norberg-Schulz that 'man dwells when he can orientate himself within and identify himself with an environment or, in short, when he experiences the environment as meaningful'. ${ }^{[59]}$

The exploration of place seems, for many authors, to lead inevitably to a further classification of the theory as the study of place over time. ${ }^{[33]}$ Henry Glassie states that 'a search for pattern in folk material yields regions, where a search for pattern in popular material yields periods' ${ }^{[60]}$ Accordingly any research on the subject must commence on the basis that 'vernacular architecture cannot be understood apart from its contents and context'. Similarly other academics have proposed that while contents, if conceived as artifacts to be studied, can be situated and viewed in relation to place, the context may only be fully understood through the parallel exploration of its development over time- as an evolution of a material culture. ${ }^{[7]}$

A key issue surrounding adaptation or unique design innovation in comparison to the broad typologies found in vernacular design is the recognition of variables. (Upton, 1983 , p.263) In a scenario where a typology is broadly identifiable yet individually variable how can a pattern be established and differentiated? Ivan Illich suggests that 'each vernacular architecture...is as unique as vernacular speech'. [61] Vernacular buildings may indeed be similar to the collation of a vocabulary and grammar- where a relatively humble subset of words, coupled with a few key working rules can allow the individual to create, in this case build, an infinite number of variable structures. ${ }^{[60]}$ Indeed it is probable that the word vernacular in itself is one originally relating to the study of regional linguistic patterns that has been appropriated by architects and architectural historians, sociologists etc. ${ }^{[51]}$ Is it possible to define the vernacular through the identification of a native order?

This concept is comprehensively considered in Alexander's A Pattern Language where he proposes that having learned to amalgamate the constituent parts of a building the success of execution is entirely within the skill base of the builder/architect/designer- the language of architecture may be, like the English language, 'a medium for prose, or a medium for poetry'. ${ }^{[24]}$ The vernacular may be characterized by the traditional/folk designer's ability to innovate within tradition and to manipulate a given grammar to restructure the hierarchy of schemata. ${ }^{28]}$

This alignment of the vernacular with the theory of language appears within research on two levels; as an analogous framework whereby the additive nature of this architecture and the obtuse nature of its authorship may be considered or as a literal method by which the cultural aspects and variations of the built environment may be filtrated through the group of social types. ${ }^{[33]}$ The diffusion of building typologies, in a similar manner to the entomology or words, can be traced or mapped through subcultures where regional identities remain intact while some aspects of construction technology and building styles are shared or intermingled. ${ }^{[62]}$

Some of the original theorists in this field have taken an almost didactic position on the value of vernacular design. Is there a 'correct' method of building, which synthesizes local knowledge and materials with aesthetic ambition? ${ }^{[63]}$ Is it possible to promote such a method to counter standardized methods that may dehumanize their inhabitants and that may offer to all the efficacy and robustness of traditional building methods. ${ }^{[64]}$ The implicit moral quality of this approach, which imbues traditional building with both adequacy and social virtue, is more often employed as a critique of architecture in the modern age than the built environment itself. ${ }^{[48]}$ The increasing grandiosity of architecture of the $19^{\text {th }}$ and $20^{\text {th }}$ circumvented cultural and traditional norms to find significance and meaning in technology and progress. ${ }^{\text {[33] }}$ As rejoinder to the 'amoral, self-expressiveness' of the new the vernacular may be appropriated as an example of a 'commitment to traditional allegiances'. ${ }^{[65]}$

However the framing of vernacular discourse in these terms presents a clear and present danger to both those in active architectural practice and research. Leon Krier has written extensively on the importance of traditional and/or familiar architectural languages as a means of maximizing the legibility of an increasingly challenging built environment. ${ }^{[66]}$ Like many countries in Europe England has a vernacular building typology that, in the face of modernization and urban growth, has been codified into a folkloristic patois. The Prince Charles backed Poundbury 
development is a riot of historicist architectural styles that does not, critically, trouble itself to reproduce the regional construction techniques or design methodologies that supported the original typologies. Indeed the reintroduction of traditional, stylistic flourishes is often the result of an overt political agenda that is sometimes nationalistic, sometimes an implicit rejection of technological process and always imbuing the subsequent built environment with the subtext of the society in which it was actually produced rather than the one it seeks to mimic. ${ }^{[67]}$

\section{Conclusions}

To be precise there is no agreed and accepted definition of the scope of vernacular architecture just as there is no formal method by which the words traditional, folk or ordinary may be omitted from the discourse. When considering where in fact the threshold between the vernacular and the non-vernacular lies we must accept a basis of inclusivity and at the least incorporate buildings that may be described as traditional, regional, anonymous, everyday, modern and contemporary. And yet does this generous boundary endanger the existence of any clarity or dynamism rendering the study of the vernacular as a diluted and ill-defined field?

This may the case and indeed perhaps this murkiness has been allowed to linger in order that researchers can enjoy the particular, and increasingly rare, freedom of a loosely defined field of study. Often it seems that the only way to define the vernacular is through an explanation of what it is not. Not made by architects, not built for import or to impress a cultural elite. It could be that vernacular architecture exists simply where the design and construction in question has been undertaken on the basis of utility although not always with reference to site and to optimize that utility for the particular needs of the building owner whether they are aesthetic or functional. I believe that perhaps the most efficacious classification for current researchers is one that, unlike monumental architectural research, does not rely on its original creator as a defining characteristic. Therefore it does not need to situate itself within folkloristic or craft construction values nor overly concern itself with morphology and adaptation. It is other than Architecture with a capital A.

However there is one clear and defining conclusion from the research undertaken- different regions and nations interpret the concept of vernacular is markedly diverse ways. In 'New World' states the relative dearth of existing built fabric has led to a far more progressive characterization of the vernacular as the architecture of the everyday while longer established nations cling to the preservation of a hand made, non-professional typology. It is the conclusion of this author that this parallel understanding of the subject matter is both a valid definition and indicative of the nature of the subject matter itself.

\section{REFERENCES}

[1] Nuttgens, Patrick. The Story of Architecture. 2nd ed: Phaidon Press Limited, 1998.

[2] Laugier, M.-A. An Essay on Architecture. Translated be W. and A. Herrmann. (Los Angeles: Hennessey and Ingalls, 1977 [1765]).

[3] Sheppard, June A. "Vernacular Buildings in England and Wales: A Survey of Recent Work by Architects, Archeologists and Social Historians." Transactions of the Institute of British Geographers 40 (1966): 21-37.

[4] Groth, Paul. "Making New Connections in Vernacular Architecture." Journal of the Society of Architectural Historians 58, no. 3 (1999): 444-51.

[5] Bloch, E. 1988 (1935). The Utopian Function of Art and Literature: Selected Essays. Translated by J.Zipes and F. Mecklenburg. Cambridge, Mass.: MIT Press

[6] Cole, Henry and Van Brunt, William. Architecture and Society: Selected Essays of Henry Van Brunt. (Belknap Press of Harvard U. Press, 1969), 121

[7] Upton, Dell. "The Power of Things: Recent Studies in American Vernacular Architecture." American Quarterly 35, no. 3 (1983): 262-79.

[8] Pawley, Martin. Architecture Versus Housing. Edited by Mary Kling, New Concepts of Architecture. London: Studio Vista 1971.

[9] Brunskill, R.W. Illustrated Handbook of Vernacular Architecture. (Faber and Faber, 1971), 21.

[10] Wells, Camille. "Old Claims and New Demands: Vernacular Architecture Studies Today." Perspective in Vernacular Architecture 2 (1986): 1-10.

[11] Brunskill, R.W. "English Vernacular Architecture." Journal of the Folklore Institute 2, no. 3 (1965): 300- 07.

[12] Hobsbawn, Eric and Ranger, Terence. The Invention of Tradition. (Cambridge University Press; Canto Ed edition, 31 July 1992), 64

[13] Rudofsky, Bernard. Architecture Without Architects: A Short Introduction to Non-Pedigreed Architecture, (University of New Mexico Press; Reprint edition 15 July 1987)

[14] Wright, Gwendolyn. "On Modern Vernacular and J.B. Jackson." Geographical Review 88, no. 4 (1998): 474- 82.

[15] Pevsner, Nikolaus. An Outline of European Architecture (Harmondsworth: Penguin, [1942] 1957), p. 23.

[16] Wotton, Henry. The Elements of Architecture: General Books LLC, 2008 (1624).

[17] Frampton, Kenneth. "Labour, Work and Architecture." In Meaning in Architecture, edited by Charles Jencks and George Baird. London: Barrie \& Jenkins, 1970. Reprint, 1.

[18] Green, Adrian. "Confining the Vernacular: The Seventheenth Century Origins of a Mode of Study." Vernacular Architecture 38 (2007): 1-7.

[19] Vellinga, Marcel. "The Inventiveness of Tradition: Vernacular Architecture and the Future." Perspective in Vernacular Architecture 13, no. 2 (2006/ 2007): 115- 28. 
[20] Zhai Z and Previtali J. 2010. Ancient Vernacular Architecture: Characteristics Categorization and Energy Performance Evaluation. Energy and Buildings, 42(3): 357-365.

[21] Oliver, Paul. Encyclopedia of Vernacular Architecture of the World.: Cambridge University Press, 1998.

[22] McKinnell, N. Michael , and Fumihiko Maki. The Pietro Belluschi Lecture Series: Lecture 4. Edited by Stanford Anderson: School Of Architecture and Planning, MIT, 1999.

[23] Stea, David. 'The Ten Smudge Pots of Vernacular Building: Notes on Explorations into Architectural Mythology' in M.Turan (ed) Vernacular Architecture: Paradigms of Environmental Response, (Avebury, Aldershot, 1990, Volume 4), 23.

[24] Alexander, Christopher. The Timeless Way of Building, (Oxford University Press, New York, 1979), 7/198

[25] Denyer, Susan. African Traditional Architecture: An Historical and Geographical Perspective: Heinemann Educational Books Ltd, 1978.

[26] Yampolsky, Mariana. The Traditional Architecture of Mexico: Thames and Hudson Ltd, London, 1993.

[27] Fitch, James Marston. 'Vernacular Paradigms for Post Industrial Architecture' in M.Turan (ed) Vernacular Architecture: Paradigms of Environmental Response, (Avebury, Aldershot, 1990) Volume 4

[28] Hubka, Thomas. "Just Folks Designing:Vernacular Designers and the Generation of Form." Journal of Architectural Education 32, no. 3 (1979): 27- 29.

[29] Rapoport, Amos. 'Defining Vernacular Design' in M.Turan (ed) Vernacular Architecture: Paradigms of Environmental Response, (Avebury, Aldershot, 1990) Volume 4, 68

[30] Upton. "The Vaf at 25: What Now?" Perspective in Vernacular Architecture 13, no. 2 (2006/2007): 7-13.

[31] Venturi, Robert, Izenour, Steven and Brown, Denise. Learning from Las Vegas, (The MIT Press; revised edition edition June 15, 1977)15/9

[32] Jackson, J.B. Landscapes: University of Massachusetts Press, 1970.

[33] Habraken, N. John. "Forms of Understanding: Thematic Knowledge and the Modernist Legacy." In The Education of the Architect: Historiography, Urbanism and the Growth of Architectural Knowledge, edited by Martha Pollack: The MIT Press, 1997), 293/68

[34] Guillery, Peter. 'Introduction; Vernacular Studies and British Architectural History' in P.Guillery (ed) Built From Below: British Architecture and the Vernacular, (Routledge, London and New York, 2011), 1-10

[35] Rapaport, Amos. Building, Form and Culture, (Prentice Hall Inc., 1969), 59/6.

[36] Lethaby, W.R. Architecture, Mysticism and Myth: Architectural Press, 1974 (1891).

[37] Brand, Stewart. How Building's Learn: What Happens after Their Built: Viking, Penguin Books Ltd., 1994.

[38] Kostof, Spiro. 'The Practice of Architecture in the Ancient World' in S.Kostof The Architect: Chapters in the History of the Profession, (Oxford University Press, 1977; third edition), 16

[39] Rosenfeld, Myra Nan. 'The Royal Building Administration in France from Charles V to Louis XIV' in S.Kostof The Architect: Chapters in the History of the Profession, (Oxford University Press, 1977; third edition), 161

[40] Ward, Colin. Housing: An Anarchist Approach, (Freedom Press, London, 1976), 121.

[41] Raglan, Lord. The Temple and the House, (Norton, New York, 1964), 34.

[42] Sheppard, June.A. 'Vernacular Buildings in England and Wales: A Survey of Recent Work by Architects, Archeologists and Social Historians', Transactions of the Institute of British Geographers 40, (1966), p.21-37.

[43] Mann, Dennis Alan. "Between Traditionalism and Modernism: Approaches to a Vernacular Architecture." Journal of Architectural Education 39, no. 2 (1985): 10-16.

[44] Rudofsky, Bernard. The Prodigious Builders: Notes Toward a Natural History of Architecture with Special Regard to those Species that are Traditionally Neglected or Downright Ignored (Harcourt Brace Jovanovich, 1977), 214.

[45] Mitcham, Carl. "Thinking Re-Vernacular Building." Design Issues 21, no. 1 (2005): 32-40.

[46] Rodriguez, Anita, and Katherine Petrus. "The Importance of Vernacular Traditions." Association for Preservation Technology International 22, no. 3 (1990): 2-4.

[47] Gottfried, Herbert and Jennings, Jen. American Vernacular Design 1870-1940: An Illustrated Glossary (Van Nostrand Reinhold Company Inc, 1985), 8.

[48] Turan, Mete. 'Vernacular Design and Environmental Wisdom' in M.Turan (ed) Vernacular Architecture: Paradigms of Environmental Response, (Avebury, Aldershot, 1990, Volume 4), 7

[49] Garfinkel, Susan. "Recovering Performance for Vernacular Architecture Studies." Perspective in Vernacular Architecture 13, no. 2 (2006/ 2007): 106-14.

[50] Bloch, E. 1988 (1935). The Utopian Function of Art and Literature: Selected Essays. Translated by J.Zipes and F. Mecklenburg. Cambridge, Mass.: MIT Press

[51] Brand, Stewart. How Building's Learn: What Happens after Their Built: Viking, Penguin Books Ltd., 1994

[52] McKellar, Elizabeth. 'The Villa: Ideal Type or Vernacular Variant' in P.Guillery (ed) Built From Below: British Architecture and the Vernacular, (Routledge, London and New York, 2011), 49.

[53] Maudlin. "Crossing Boundaries: Revisiting the Thresholds of Vernacular Architecture." Vernacular Architecture 41 (2010): 10-14.

[54] Vellinga, Marcel. "The Inventiveness of Tradition: Vernacular Architecture and the Future." Perspective in Vernacular Architecture 13, no. 2 (2006/ 2007): 115- 28

[55] Colquhoun, Alan. Modern Architecture (Oxford History of Art), (Oxford University Press, 2002), 32.

[56] Armstrong, J.R. Traditional Buildings-Accessible to the 
Public. (EP Publishing Ltd, 1979), 9

[57] Heath, Kingston Wm. 'Assessing Regional Identity Admindst Change: The Role of Vernacular Studies', Perspectives in Vernacular Architecture 13, no.2 (2006/2007): 76-94.

[58] Mumford, Lewis. Sticks and Stones: A Study of American Architecture and Civilization. 2nd (1924) ed: Dover Publications, New York, 1955.

[59] Norberg-Schulz, Christian. Genius Loci: Towards a Phenomenology of Architecture, (Rizzoli, 1979), 112.

[60] Glassie, Henry. Pattern in the Material Folk Culture of the Eastern United States. (Philadelphia University of Pennsylvania 1968), 33.

[61] Illich, Ivan. In the Mirror of the Past (London, New York: Marion Boyars, 1992), 56.

[62] Husa, V., Petran, J. and Subrtova, A. Traditional Crafts and Skills: Life and Work in Medieval and Renaissance Times. (Paul Hamlyn, Prague and London, 1967), 32.
[63] Morris, William and Miele, Chris. William Morris on Architecture, (Continuum International Publishing Group Sheffie, 1996), 8

[64] Ruskin, John. The Ethics of Dust, (CreateSpace Independent Publishing Platform, 2012 [1866]), 71

[65] Landau, Royston. "Architecture, Ethics and the Person." In The Education of the Architect: Historiography, Urbanism and the Growth of Architectural Knowledge, edited by Martha Pollack: The MIT Press, 1997.

[66] Krier, Leon. Architecture: Choice or Fate. (Papadakis Publisher, 1998), 148.

[67] Maudlin, Daniel. "Constructing Identity and Tradition: Englishness, Politics and the Neo-Traditional House." Journal of Architectural Education (2009): 51-63. 